\title{
UTILIZATION OF SCHOLARLY JOURNAL ARTICLES IN THE TEACHING AND LEARNING OF TEACHER EDUCATION COURSES
}

\author{
Derren N. Gaylo ${ }^{1}$ Manuel E. Caingcoy ${ }^{2}$ Daisy C. Mugot ${ }^{3}$ \\ ${ }^{1}$ Assistant Professor, Bukidnon State University, Philippines, gaylo_derren@buksu.edu.ph \\ ${ }^{2}$ Assistant Professor, Bukidnon State University, Philippines, caingcoy101379@gmail.com \\ ${ }^{3}$ Associate Professor, Bukidnon State University, Philippines, dey_mugot@yahoo.com
}

\begin{abstract}
The usage of scholarly journal articles in the academe is now gaining attention to cope with the ever dynamic and evolving teaching and learning processes. However, the use implies possible potential usage only because what is measured is the number of views and downloads of the articles. This paper explored how the teacher education faculty and students utilized scholarly journal articles in the teaching and learning of professional education courses. The study also determined the challenges in using these primary sources and documented ways of overcoming them. Data were organized and analyzed using a thematic narrative technique of Riesman as the analytical framework. The inquiry was participated by six faculty and six students from the College of Education at a state university in Northern Mindanao in the first semester of the school year 2019-2020. The necessary protocol was followed, and ethical considerations were secured before the conduct of the study. An informed consent form was presented to each participant before they signed it, signifying that they are not forced to participate in the study. The faculty had a focus group discussion, while the students had a face-to-face interview with the researchers. Emerging themes revealed that scholarly journal articles were utilized by exposing learners to varied writings, enriching course content and learning, exposing them to process learning, preparing learners for classroom engagement, guiding learners to produce outputs, and allowing learners to acquire updates. The inquiry reported challenges in terms of the capability of the learners, interest and perception of learners, and the journal itself and its contents. Documented ways of overcoming these challenges include time management, frequency of use, selection criteria, and checking the author's background.
\end{abstract}

Keywords: Journal Articles, Narrative Inquiry, Teacher Education, Teaching, Learning

\section{INTRODUCTION}

The growing availability of scholarly articles online allows instructors to use such literature functional to teaching (Langston \& Tyler, 2004), and it paves the way for more scholarly learning to rise. Scholarly articles, which are peer-reviewed research-based works written by experts on specific fields (California State University, 2011), are usually published by the academe and organizations often subscribed by individual scholars and libraries (Ohio State University, 2016).

The usage patterns of scholarly articles in the web has been investigated by many researchers because journal publications are considered most credible sources with the rigorous peer-review process (Larsen, 2013) and function a very important role for learning, teaching, and research in

any university (Bamidel, Omeluzor \& Amadi, 2013). However, the use implies possible potential usage only because what is measured is the number of views and downloads of the articles, and does not mean it was used by just viewing and downloading it (Wang, Fang \& Sun, 2016). The manner these articles were used in the classroom has to be explored, including the challenges that inhibit their use and how users overcome these challenges. 
Primary sources, like scholarly articles, play an important role in providing students with authentic, constructive learning experiences that help them learn to think by exercising higher-order skills (Newman, Degener \& Wu, 2015). The scholarly articles not only describe the nature of the scientific process, but also lead learners to assess data critically, develop their scientific writing, and be updated of the current advances in research (Round \& Campbell, 2013).

Studies that involved students include the utilization of journal publications or e-journals (Bamidele et al., 2013; Acheampong, Boakye \& Agyekum, 2019; Faizul \& Naushad, 2013) and underutilization of these resources (Azam, Shaheen, Shaikh, Sheikh, Siddiqui, Zafar \& Nismat, 2018), access to e-journals (Acheampong et al., 2019), patterns on the use of print and electronic journals (Gupta, 2011), awareness towards the use of e-journals (Faizul et al., 2018), teaching students to read the primary literature (Murray, 2013), factors that influence the usage of academic journals (Saxena, 2018), and the impact of field specialization on internet resource usage (Sriram, 2014).

Several studies involved instructors on the usage of e-journal amongst lecturers (Bakar \& Ariffin, 2013), the use of new resources to teach evidence-based practice (Heye \& Stevens, 2009), the use of classroom-based and web-based historical primary sources among social studies instructors (Hicks, Doolittle \& Lee, 2004), use of e-journals by research scholars (Kumar \& Reddy, 2014), use of journal articles in an online teaching environment (Langston \& Tyler, 2004), awareness and the use of scholarly electronic journals among of academic staff (Msagati, 2014), and on how instructors use primary sources to meet the common core literacy standards (Newman et al., 2015). Furthermore, scholarly articles are used also for content delivery (Swan \& Locascio, 2008), for research purposes (Madhusudhan, 2008), to enhance student learning in high school and college courses (Grant, Gradwell, \& Cimbricz, 2004) and increasing the critical thinking skills of the students (Gottesman \& Hoskins, 2013).

However, the freedom to easily access information, like scholarly articles on the web, allows the selection of information that may cause confusion or misinformation (Colepicolo, 2015). Academic researchers, usually instructors and students, have to select scholarly articles that are suited to their objectives, credible, appropriate, and of high quality. There are times that academic publications are ignored by other researchers due to various reasons: they know that conclusions may eventually be verified as erroneous; publications are sometimes withdrawn; effects may weaken when studied subsequently; scholars occasionally do not appear to know about the papers they have authored; and there are even complaints of fraud (Fahy, 2013). Generally, there must be permission from the copyright owner to use the articles. Fortunately, copyright law provides some exceptions to this general rule that allows educators to make use of materials in these ways, provided they follow definite guidelines or criteria (American University Library, 2010).

Inaccessible sources may limit the instructors' actual use of both classroom-based and web-based primary sources (Hicks et al., 2004). Larsen (2013) even cited that some scholarly articles are written too hard to be understood by students. Online journals were underutilized according to Azam and colleagues (2018) due to an overfamiliarity with books, a lack of faculty prompting, and a lack of knowledge on how to access journals. Unless otherwise required in a class, students rarely use online journals (Tenopir, Pollard, Wang, Greene, Kline, Krummen \& Kirk, 2003).

Professional Education courses like Educational Assessment, Curriculum Development, Teaching Strategies, and Child and Adolescent Development have a limited number of documented studies exploring the use of scholarly articles in the teaching and learning processes. An inquiry on how faculty and students used scholarly articles in the academe had been conducted to have useful information as feedback on the importance of using research-based resources to improve the quality of teaching and learning most especially in developing students' higher-order thinking skills for them to thrive in the 21 st century.

Thus, the study explored the utilization of scholarly journal articles in teaching and learning professional education courses in a Teacher Education setting. Specifically, it explored how higher education faculty and students use these articles, determined challenges that inhibited their use, and find out how the users overcome those challenges. The results of this inquiry may add to the frontiers of knowledge on the use of scholarly journal articles for teaching and learning purposes and may lead to policies on its usage.

\section{METHODOLOGY}

The study used a narrative inquiry methodology. Narrative inquiry is a qualitative research that involves gathering of narratives aiming at the meanings that people attribute to their experiences to provide insights on the phenomenon under study (Josselson, 2006). The inquiry was participated by six faculty and six students from the College of Education at a state university in Northern Mindanao in the first semester of the school year 2019-2020. The necessary protocol was followed, and ethical considerations were secured 
before the conduct of the study. An informed consent form was presented to each participant before they signed it, signifying that they are not forced to participate in the study. The faculty had a focus group discussion, while the students had a face-to-face interview with the researchers.

Data were organized and analyzed using a thematic narrative technique of Riesman (1993) as the analytical framework since the study is focused on individual experiences in using scholarly journal articles for teaching and learning purposes. This framework follows the three steps. First, each transcript was read very diligently. It allowed the researchers to detect the apparent narratives that answer the research problem. Second, those evident narratives or excerpts were grouped according to identified themes. This stage allowed researchers to experience a deeper immersion in the text. In the third stage, the researchers were looking into the commonalities and similarities among excerpt narratives about the themes. The study derived themes from the common narratives and the selected narratives to support the discussed themes. These themes and narratives were presented back to the participants for confirmation before it was finalized.

\section{RESULTS AND DISCUSSIONS}

\subsection{How Journal Articles Were Utilized in Teaching and Learning}

The first set of themes center on how journal articles were utilized in teaching and learning professional education courses. According to instructors and students, they used journal articles for exposing learners to varied writings, enriching course content and learning, exposing learners to process learning, preparing learners for classroom engagement, guiding learners to produce outputs, and allowing learners to acquire updates.

\subsubsection{Exposing Learners to Varied Writings}

Scholarly journal articles were utilized in teaching and learning the professional education courses for unlocking purposes. It was acknowledged that these learning materials were typically written in the research language intended for a well-chosen audience. Learners were challenged to understand the meanings of each term used. Aside from comprehension, these materials were utilized to achieve the goal of the course, that is, to exposed learners in different writings. And so, one instructor found it necessary to use the terms of the articles for unlocking purposes and for ensuring better comprehension of the learners. She narrated that:

In the developmental reading, the main goal is to develop their comprehension skills. I always used unlocking before they read the articles because you know, as I had said when we exposed them to journal articles, the articles are field with difficult words, adult words, technical or scientific terms. They would learn the course better because they would get it right from the experts, the authorities saying the concepts to them and not just me. And then they also learned the language on the side, expressing themselves in formal discourses (Instructor 1).

It has been claimed by Larsen (2013) that scholarly articles are the most credible sources because of the rigorous peer-review process. Yet these sources were written for experts, and not for undergraduate students. Thus, this would make journal articles challenging to understand for college students. With these, instructors have to aid students to learn the language of research to lessen and manage their difficulties when they use scholarly journal articles for learning purposes.

\subsubsection{Enriching Course Content and Learning}

It was observed that some professional education courses do not have abundant teaching and learning resources. As such, the situation paves the way for using journal articles that may enrich the content of the course they are teaching. In doing so, literature becomes functional in teaching (Langston \& Tyler, 2004). One instructor keeps on repeating similar authorities across chapters in the syllabus. To enrich the content of the subjects she teaches, the instructor indicates the importance of using journal articles and reading them ahead of students. Otherwise, it would not serve the purpose and the instructor may not explain the content very well. An instructor expressed that:

If you go over our syllabus, it's very limited and it is like if you try to look on our syllabus they are commercialized like in Chapter 1 it seems to be from one author until the last topic. And so it limits us on the references and there are times that I asked my students to read an article which I make sure I read it first (Instructor 3).

Relevant to this theme, a student shares her experience with her instructor in the Assessment of Learning course that every time they are tasked to do a reporting in class, they were instructed to always use credible sources. One of those they used was journaled articles. Their instructor emphasized the importance of citing 
authorities of the content. Therefore, content enrichment would mean citing credible sources.

Aside from the limited teaching and learning resources of professional education courses, content enrichment would be in the form of choosing journal articles over books since they usually have literature reviews. That alone can enrich both the content and students' learning. Normally, these sources have more recent and updated information from the reviewed previous studies.

On the other hand, journal articles were used to enrich the learning of students. One student shared that they were instructed to read a published journal article as a basis in developing their topic for reporting. One student mentioned also that in some professional education subjects, their instructors required them to use journal articles for a better and deeper understanding of the lesson. These narratives from students indicated the theme above:

In the assessment of learning, I can still remember that every time we do a report we need to state according to an author. We discussed lessons in class based on published studies (Student 1).

I become more knowledgeable. I become more aware of information from researches other than information from the books (Student 2).

The article was made as a basis for our topic in reporting. We were instructed to draw an understanding of the article. It's like an essay. For me, as a college student, I need to always use journal articles (Student 3).

Your learning would be enhanced. I would have a deep and wide understanding of the lesson. After the lesson was discussed by my instructor, I did some readings from articles. I would not rely on how the instructor discussed it (Student 4).

Scholarly articles are part and parcel of the content delivery (Swan \& Locascio, 2008) which enhance student learning (Grant et al., 2004). These primary sources play a vital role in ensuring authentic and constructive learning experiences that help them learn and exercise higher-order thinking skills (Newman et al., 2015). Indeed, these learning sources can enrich course content and student learning.

\subsubsection{Exposing Learners to Process Learning}

Some courses are too content-driven while some emphasized the learning of the processes. One instructor on Principles of Teaching allowed the use of journal articles so that the learners could learn the process or methods of teaching. It is a fact that the principles of teaching as a course is procedural as it deals with approaches, methods, and teaching strategies.

The said instructor used these materials when she taught students on the problem-based method. With the concept itself, journal articles contain a problem, the methodology, and how the problem was addressed or given solution. Research articles depict the nature of the scientific process (Round et al., 2013). Thus, these good materials for students to learn the processes of problem-based teaching or learning. One instructor shares that:

I used an article when I taught a problem-based method in Principles of Teaching. So I tried to look into the steps actually and then I let my students identify. They go through the steps of providing answers or providing what is being asked through the article being used. There's a step wherein the students need to analyze the problem scenario and so they were able to do that and then the second one is list what is known. They need to provide the necessary data from the article (Instructor 5).

\subsubsection{Preparing Learners for Classroom Engagement}

Allowing students to acquire prior knowledge or information on the topic may help them learn well the lesson. For this purpose, some instructors opted to allow learners to choose journal articles at their choice, or sometimes they provided them with a specific title and author of the articles so that it would be easier for the learners to look for and use these articles. Two instructors cited below how they prepared students for classroom engagement using journal articles:

I remembered that I asked my students in the Child and Adolescence course to look for a problem that is related to children, child, and development thing. Well, it was just a simple activity that served as an assignment. I just asked them to decide a topic, to look at the methodology used, the problem, and the solution (Instructor 1).

In my case, there are times that I just asked them to read a research article or journal article 
related to our topic. But there are also sometimes I tell them a specific title of a research article that I have read myself. So, the subjects that I could remember that I used journal articles are in curriculum and development specifically John Biggs when I got to know the concept of constructive alignment which is new to the curriculum. I asked my students to refer to a certain reference that is a journal article. And then I asked them to read it. The session after we had processing where I was able to ask them questions from the journal (Instructor 3).

Instructors mentioned how they used journal articles. Accordingly, there would be better engagement in class between the instructor and students when the former read in advance and formulates the questions from the article assigned to students. On the other hand, students would become engaged in class if they can prepare and eventually participate in the processing stage. Preparing learners for classroom engagement purposes was supported by a student narrative:

In Principles of Teaching course, we experienced self-reading. We were tasked to look for studies related to the topic. It was a bit challenging but I liked it because we can explore on our own. When we come to class, I share, then our instructor provides us and discusses to us relevant researches (Student 5).

With these narratives above, the claim is evident that a variety of approaches in using scholarly articles in the classroom where students may work on different articles in the same subject area or use only a single article in the class (Murray, 2013).

\subsubsection{Guiding Learners to Produce Outputs}

Scholarly journal articles have an essential purpose for learning, teaching, and research (Bamidel et al., 2013). One faculty recalled how she utilized scholarly journal articles in teaching research both the introduction and that of the major course. The former course was preparatory to the other. The way journal articles were used here serves as a guide for students to be able to familiarize the parts, identify the contents, and eventually, they have to make their research papers. The research course was taught here in a systematic manner following the steps and the order of activities that can be found in journal articles. In verbatim, a faculty said:

In my case, I have an introduction to research, particularly, I always refer to some articles. They have already the proposed topic that they would like to study. And in that case, I asked them to look for articles that are related to their identified subject. And then part-by-part I introduced to them. From time to time, we refer to the articles in determining what is present in the abstract, what methodology is used. So practically, the article is a guide for them as to how they are going to construct their paper specifically that it's a major. Later on, they will have their major subject in Early Childhood Education. They have to be guided as to how they are going to make their paper (Instructor 4).

\subsubsection{Allowing Learners to Acquire Updates}

One instructor emphasizes the importance of getting updates using scholarly journal articles. Students need to be updated especially with the Basic Education curriculum. They have to learn from studies on critical thinking, creativity, communication, and collaboration that can be considered in their lesson planning. She said:

Articles are really helpful to the students so that they can understand the new curriculum of $K$ to 12 wherein the $\mathrm{K}$ to 12 is based on $4 \mathrm{Cs}$ or the 4 skills- the critical thinking skills, collaboration, creativity, and communication. It's also one way of orienting the students on how to use the new technology (Instructor 2).

Students use scholarly journal articles even if they are not told to do so. They did it because they want to get more information and factual updates for their writing hobbies. Accordingly, research articles do not only depict the nature of the scientific process, but also train students to evaluate data critically, improve their scientific writing, and follow the most recent advances in research (Round \& Campbell, 2013). But when they are asked if they use these resources without the influence of any instructor, and for what purposes, one responded:

I love reading facts and then I do some writings. That's why sometimes I can say our instructors are right that we use researches so that we would become aware of the different happenings around the world (Student 6).

Aside from the fact that research articles depict the nature of the scientific process, they also train students 
to evaluate data critically, improve their scientific writing, and follow the most recent advances in research (Round \& Campbell, 2013). These articles are major resources with current and up-to-date information (Bamidele et al., 2013). Thyer (2008) contended that peer-reviewed articles are an important part of keeping up with current trends and research in any academic field.

\subsection{Challenges Encountered by Faculty and Students in Utilizing Scholarly Articles}

The next sets of themes describe the challenges encountered by instructors and students in utilizing journal articles in teaching and learning professional education courses. These challenges are clustered into three: capability of the learners, interest, and perception of learners, and the journal itself and its contents.

\subsubsection{Capability of the Learners}

Capability-related challenges are some of the reasons why some students do not have much confidence in using scholarly journal articles in learning professional education courses. This is something to look into by instructors when they use peer-reviewed articles in teaching these courses. This lack of capability is also demonstrated in their dependence on the few able members of the class. Instructors narrated:

I also found out during the activity the students are not very good at looking into the methodology. They really cannot identify what method is used (Instructor 4).

They have difficulty in understanding a certain word and the more they will not be able to understand the entire article (Instructor 3 ).

The problem is when they are grouped; others or most of them are free riders. They will depend only on the few (Instructor 5).

At some point, we could reflect because they were not exposed to critical reading. Even if they had read a lot of articles they couldn't get the point of that article. They could use what is suited to their research. However, they were not exposed to it. Maybe it is a point for reflection (Instructor 2).

The number of challenges shared above and all draw-back to the capability of learners in using the scholarly journal articles. This is worth noting that the difficulties above could be attributed to the lack of exposure of learners to using these primary sources. Learners could have been provided with ample opportunities where they could capacitate themselves to read and think critically. Critical thinking is an important learning skill in the twenty-first century.

\subsubsection{Interest and Perception}

Three of the interviewed instructors observed that their students had less interest in the use of scholarly journal articles. This challenges them to motivate learners to engage in using these materials for learning. One of them attributed this problem to their interest, as they perceive it. Accordingly, students perceived scholarly journal articles as difficult to use. This confirmed the previous findings that the factors impacting the usage of academic journal articles in Indian universities among Ph.D. students were linked to the motivation of students (Saxena, 2018). These instructors shared that:

Some students are not that interested that is why they do not get the point or the idea about the article (Instructor 5).

The major challenge is on motivating them to read because the first impression that they have is that it is boring (Instructor 1 and 6).

Even before reading it, they lost interest and so that is one major challenge for all the instructors (Instructor 3).

\subsubsection{Journal Itself and Its Contents}

Most scholarly journal articles underwent a rigorous process of editing and peer-reviewing done by experts before it was published. With this, the language of research was integrated into it when these experts have done their roles. Before the peer review, the authors themselves write in the language common to their fields. These parameters learners and instructors themselves encountered challenges in using scholarly journal articles. Again, scholarly journal articles are peer-reviewed and research-based works written by experts (California State University, 2011). This theme is indicated in these narratives:

The articles contain very difficult words, adult words, technical or scientific terms (Instructor 2 and 5).

It is more on the text and it is quite long (Instructor 4). 
Students have this connotation that when we give them research reading or research or journal article to read. They would conclude that it is really difficult. They did not read it because maybe one of the factors was the mindset that it was really difficult. Because of the established jargon that is difficult (the language of research) and our students are not used to that (Instructor 3).

More often, journal articles use words that are unfamiliar to me and they have deep meanings (Student 3).

The freedom to easily access information, like scholarly articles on the web allows the selection of information that may cause confusion or misinformation (Colepicolo, 2015). Academic researchers, usually instructors and students, must be able to select scholarly articles that are suited to their objectives, credible, appropriate, and of high quality. One student participant shared this:

Sometimes, I got confused. There are conflicting facts and claims. I find it hard which study to choose and believe (Student 1).

\subsection{How to Overcome the Challenges Encountered in Utilizing Scholarly Articles}

The third set of themes is inclusive of the ways the professional education instructors and students overcome the challenges and difficulties in using scholarly journal articles. In this section, four themes below are cited: time, frequent use, selecting the best articles and checking the authors' background.

\subsubsection{Time}

They have to read it first before they come to class and then you have to provide them the guide questions before reading. So that they can determine what is necessary to take note of the moment they are to read the articles (Instructor 4).

\subsubsection{Frequent Use}

You have to engage yourself in these materials and you use them often (Student 2).

\subsubsection{Selecting the best Articles}

I chose the study which is more applicable in different situations and ones that provide the best support and result (Student 5).

\subsubsection{Checking the Authors' Background}

In times of conflicting claims, I checked who wrote and published it. I checked the background of the researchers before I choose (Student 1).

\section{GENERAL STATEMENT}

In the past, a study was not certain if journal articles were utilized since it focused on usage patterns only (Wang et al., 2016). However, the present inquiry documented that scholarly journal articles were utilized in the teaching and learning of professional education courses. This utilization had varied purposes ranging from exposing learners to varied writings, enriching course content and learning, exposing learners to process learning, preparing them for classroom engagement, guiding them to produce outputs, especially in research, to allow them to acquire updates in their respective fields.

Both instructors and students had encountered challenges in utilizing these journals, however, these challenges did not stop them. They had unique ways of overcoming these challenges. One of the challenges was on the capability of learners which can be linked to their critical thinking skills, while the other has something to do with the nature of journal articles particularly on the research language on which these resources are written. Another challenge that needs to be addressed was the interest and perception of learners toward scholarly journal articles. Some students were challenged when they had read conflicting facts and claims. These results imply for instructors to use journal articles very creatively not only making them as sources of information or course content. Instructors need to design and plan varied ways of utilizing these primary sources to entice learners to use them more frequently and learners' exposure to these sources must be done earlier in their university journey.

This study has limitations. Future researchers may consider other research methodologies, larger scope, and different disciplines to explore the use of scholarly journal articles in their context. This is relevant nowadays due to the scholarship of teaching and learning. 


\section{ACKNOWLEDGEMENT}

This work was funded by the Bukidnon State University Research Unit. The researchers were grateful for the generous funding extended by the University for this endeavor.

\section{REFERENCE LIST}

Acheampong, S. A., Boakye, E. \& Agyekum, B. O. (2019). Access and use of e-journals by students of Kumasi Technical University, Kumasi, Ghana. Library Philosophy and Practice (e-journal), 2327.

American University Library. (2010). What Faculty Need to Know About Copyright for Teaching. USA: American University Library.

Azam, F., Shaheen, A., Shaikh, F., Sheikh, A. A. E., Siddiqui, F. S., Zafar, A. \& Nismat, J. (2018). Underutilization of Research Journals by Undergraduate Students of Medical Colleges in Islamabad: A Cross-sectional Study. Cureus, 10 (5).

Bakar, A. B. A. \& Ariffin, M. Y. M. (2013). The Usage of E-Journal Amongst Lecturers at a Public University in Malaysia. TOJET: The Turkish Online Journal of Educational Technology, 12 (2), 321-329.

Bamidele, N. J., I. A., Omeluzor, S. U. \& Amadi, H. U. (2013). Utilization of Journal Publications by Undergraduate Students of Babcock University, Nigeria. Library Philosophy and Practice (e-journal), 1006.

California State University. (2011). What is a scholarly article? Retrieved from http://libguides.csuchico.edu/scholarly

Colepicolo, E. (2015). Information reliability for academic research: review and Recommendations. New Library World, 116, (11 \& 12), $646-660$.

Fahy, P. (2013). Uses of Published Research: An Exploratory Case Study. The International Review of Research in Open and Distance Learning, 145- 166.

Faizul, N. \& Naushad, A. P. M. (2013). Awareness and use of e-journals by IIT Delhi and Delhi University library users. Collection Building, 32 (2), 57-64. DOI:10.1108/0160495131 1322039

Gottesman, A. J. \& Hoskins, S.G. (2013). CREATE cornerstone: introduction to scientific thinking, a new course for STEM-interested freshmen, demystifies scientific thinking through analysis of scientific literature. CBE Life Sci Educ. Spring;12(1):59-72.

Grant, S.G., Gradwell, J.M. \& Cimbricz, S.K. (2004). A question of authenticity: The document-based question as an assessment of students' knowledge of history. Journal of Curriculum and Supervision, 19(4), 309-337.

Gupta, D. K. (2011). Use pattern of print and electronic journals at the Kurukshetra University, India. Program, 45 (2), 213-230.

Heye, M. L. \& Stevens, K. R. (2009). Using New Resources to Teach Evidence-Based Practice. Journal of Nursing Education, 48 (6), 334-339.

Hicks, D., Doolittle, P. \& Lee, J. (2004). Social Studies Instructors' Use of Classroom-Based and Web-Based Historical Primary Sources. Theory \& Research in Social Education, 32(2), 213-247.

Josselson, R. (2006). Narrative research and the challenge of accumulating knowledge. Narrative Inquiry, 16(1), 3-10.

Kumar, M. A. \& Reddy, V. (2014). Use of E-Journals by Research Scholars in University Libraries in Andhra Pradesh. Library Philosophy and Practice(e-journal), 1086.

Langston, M. \& Tyler J. (2004). Linking to Journal Articles in an Online Teaching Environment: The Persistent Link, DOI, and OpenURL. Internet and Higher Education, 7(1), 51-58.

Larsen, A. (2013). Scholarly Sources. Lone Star CyFair Writing Center. Retrieved from http://www.lonestar.edu/departments/tutoring/Scholarly_Sources.pdf

Madhusudhan, M. (2008). Use of UGC-Infonet e-journals by research scholars and students of the University 
of Delhi, Delhi: A study. Library Hi Tech, 26 (3), 369-386. DOI:10.1108/07378830810903300

Msagati, N. (2014). Awareness and Use of Scholarly Electronic Journals by Members of Academic Staff: A Case Study of Dares Salaam University College of Education (DUCE). Library Philosophy and Practice, 1124.

Murray, T. (2013). Student Centered Education: Teaching Students to Read the Primary Literature Using POGIL Activities. Biochemistry and Molecular Biology Education, 165-173.

Newman, M., Degener, S., \& Wu, X. (2015). How are instructors using primary sources to meet Common Core literacy standards in English/Language Arts, Social Studies, and Science? NCE Research Residencies. Paper 1.

Ohio State University (2016). What are Professional or Scholarly Journals? Retrieved from https://newark.osu.edu/ library/help/articles-and-databases.html

Riesman, C. K. (1993). Narrative Analysis. Newbury Park: Sage Publications.

Round, J. \& Campbell, M. (2013). Figure Facts: Encouraging Undergraduates to Take a Data-Centered Approach to Reading Primary Literature. CBE-Life Sciences Education, 12(1), 39-46.

Saxena, S. (2018). Factors impacting the usage of academic journal articles by $\mathrm{PhD}$ students in India. Information Discovery and Delivery, 46 (4), 204-213. DOI:10.1108/ IDD-09-2017-0069.

Sriram, B. (2014). Specialization Impact on Internet Resource Usage: Omani Undergraduate Learner's Perspectives. International Journal of Modern Education and Computer Science, 6 (8), 10-17.

Swan, K., \& Locascio, D. (2008). Alignment of technology and primary source use within a history classroom. Contemporary Issues in Technology and Instructor Education, 8(2), 175-186.

Tenopir, C., Pollard, R., Wang, P., Greene, D., Kline, E., Krummen, J. \& Kirk, R. (2003). Undergraduate Science Students and Electronic Scholarly Journals. ASIST 2003, Contributed Paper 291-297.

Thyer, B.A. (2008). Preparing research articles. New York : Oxford University Press.

Wang, X., Fang, Z. \& Sun, X. (2016). Usage patterns of scholarly articles on Web of Science: a study on Web of Science usage count. Scientometrics. DOI:10.1007/ s11192-016-2093-0. 